\title{
Addressing the Educational Needs of Children with Williams Syndrome: A Rather Neglected Area of Research?
}

\author{
Olympia Palikara' ${ }^{1} \cdot$ Maria Ashworth $^{2} \cdot$ Jo Van Herwegen ${ }^{2}$
}

() Springer Science+Business Media, LLC, part of Springer Nature 2018

\begin{abstract}
Williams syndrome (WS) is a rare neurodevelopmental disorder associated with physical health problems, limitations in cognitive abilities and increased risk of mental health difficulties. This profile of complex needs may make it challenging to support children with WS in schools. Surprisingly, in the current international move for inclusion, limited research exists on the educational provision and academic achievements of children with WS, including the non-existing literature on their voices and the perspectives of key stakeholders. This letter calls for additional research on the risk and protective factors associated with the educational outcomes of these children, the perspectives of the children themselves and the development of the evidence-base about the effectiveness of education intervention programs.
\end{abstract}

Keywords Williams syndrome · Educational provision · Academic achievements · Transition · Interventions

Williams syndrome (WS) is a rare genetic neurodevelopmental disorder that affects 1 in 20,000 births (Morris and Mervis 1999) and is caused by a micro-deletion of at least 27 genes on chromosome 7q11.23 (Koehler et al. 2014). It is generally diagnosed based on the clinical profile as well as by a blood test to confirm the genetic deletion, either through a fluorescent in situ hybridization (FISH) test or micro-array analysis. Children and young people with WS experience associated physical health problems, including renal abnormalities and cardiovascular difficulties, in the light of impaired cognitive development, which ranges between mild to severe intellectual impairment (Martens et al. 2008). Children and young people with WS have varied and uneven cognitive and behavioural profiles. Although they show relative strengths in face perception and auditory short-term memory, have a high drive for social interaction, and affinity with music, they also present with delayed and atypical language development (especially verbal comprehension), spatial cognition, and number development (Van Herwegen 2015). Additionally, they are at increased risk of

$\triangle$ Olympia Palikara

Olympia.Palikara@roehampton.ac.uk

1 School of Education, Froebel College, University of Roehampton, Roehampton Lane, London SW15 5PJ, UK

2 Department of Psychology, Kingston University London, London, UK developing behavioural and mental health difficulties including anxiety, attention deficit and hyperactivity disorders, and affective disorders (Riby et al. 2014).

The unique pattern of relative strengths and impairments described above suggest that supporting the complex needs of these children in education settings may require specific knowledge, approaches and support by educators, professionals, and families. However, to date there is a dearth of information concerning: (1) where children with WS are educated; (2) the academic achievements and needs of these children, especially during critical developmental periods, such as the transition from primary to secondary education; (3) evidence-based interventions that can support their educational and psychosocial development. The limited evidence-base concerning the educational needs/achievements of children and young people with WS is rather surprising, if one takes into account that their cognitive profile has been the focus of extensive research over the last 40 years (Howlin et al. 1998, 2009). This letter briefly reviews the existing literature to date with regards to these issues and calls for the development of a relevant research base, especially in the light of the need for evidence-based targeted educational interventions and various international policy calls for inclusion and raising the achievements of all children and young people with special educational needs. 


\section{Educational Provision for Children and Young People with WS}

Although there are still ongoing debates about the rights of children with special educational needs and disabilities (SEND) to be educated in mainstream settings, there is an increasing international trend for pupils with SEND to attend mainstream schools (DfE 2017; Lindsay 2007). WS is a rare developmental disorder, but little is known about the context that children with WS are being educated and the support they receive in these placements in the light of the ongoing climate of commitment to inclusive education regardless of disability. One notable recent exception concerns a comparative study in the UK, which examined the educational provision of children with rare developmental disorders, including WS, based on parent and teacher reports. The findings suggested that a reduced number of children attend mainstream secondary education when compared to primary (Reilly et al. 2015b). However, the results of this study, except for the type of provision attended, provided limited insight about the level of support that the children with WS were receiving in order to have their needs met.

Additionally, even though a few studies have examined the views of parents and professionals (Fidler et al. 2003; Fisher and Morin 2017; Reilly et al. 2015a, b), there is a shortage of information on the perspectives of key stakeholders about the educational provision of children with WS, especially about the particular facilitators or barriers that affect their inclusion. Studies on the views of key stakeholders in WS are essential, as previous research in other developmental disorders has now established that professionals' knowledge and understanding are key factors in determining the successful inclusion in school settings (Humphrey and Lewis 2008; Lindsay et al. 2013). With exception of Fisher and Morin (2017), studies are literally non-existing concerning the voices of the children and young people with WS themselves regarding various aspects of their educational lives. The need for the views of these children to be heard about their education, health, and care needs is imperative for research, and practice internationally (DfE 2015; Individuals with Disabilities Education Act 2004) as several policy documents highlight their right to choice and individual agency for effective participation and inclusion of people with disabilities in society.

\section{Educational Transitions and WS}

Transition periods, such as the move from primary to secondary school, places substantial social, intellectual, organisational, and emotional demands upon pupils and is considered to be one of the greatest challenges in a young person's educational career (Riglin et al. 2013). This may be particularly true for pupils with WS who, except for the difficulties related to the elevated demands of the curriculum, may have to deal with the increased levels of anxiety caused by the changes in the structure and quantity of support they are receiving. For example, although people with WS are extremely sociable, they have difficulties with establishing meaningful peer-relationships (Järvinen et al. 2013). In addition, children and young adults with WS often experience higher levels of anxiety and limited adaptive behaviours (Mervis and Klein-Tasman 2000). Children and young people with WS rely more on a structured environment and thus, transitions which impacts on their daily routines, familiarity of the support staff and peers, can be more problematic for them.

However, to date little is known on the effect of transition from primary to secondary school on the educational and psychosocial outcomes of children with WS. Additionally, there is limited evidence how the important people in the lives of children with WS perceive this transfer and the risk and protective factors associated with transition. Further information about how transitions impact children with WS and their families is essential in planning, supporting, and raising the educational achievements of the children during the critical time of move from primary to secondary education.

\section{Lack of Evidence-Based Educational Interventions}

Given the fact that WS is a genetic disorder that can be diagnosed early in life, it is in theory possible to provide interventions, adaptations and/or supports. However, in practice there are very few interventions for children with WS and the evidence-based evaluation of educational interventions and therapies for WS is limited. For example, although it has been suggested that based on their cognitive profile children with WS may benefit from the use of computers and calculators to access learning, and that verbal mediation strategies may improve academic outcomes (Dykens et al. 2000), there is currently a dearth of research evidence that backs up these suggestions. It should be noted that some notable exceptions suggest that using the cognitive strengths of people with WS can improve their learning difficulties. For example, music therapy has been shown to improve WS children's mathematical abilities (Reis et al. 2003) and verbal working memory abilities to learn new words (Dunning et al. 2015).

Although it is well-established that a large proportion of children with WS experience overall cognitive impairments, especially visuo-spatial, working memory, language comprehension, planning, and number abilities (Howlin et al. 
2009), there is a scarce of evidence-based information on the effect that these difficulties have on their literacy (including reading, reading comprehension and writing), numeracy skills, and the academic achievements during primary and secondary education (Steele et al. 2013). Understanding the factors that may predict, hinder or enable the educational achievements of children and young people with WS may be of crucial importance for developing and putting in place evidence-based interventions for children and young people with WS and for raising achievement for this group of children.

Although it can be argued that aetiology-based interventions may have a larger impact on the learning outcomes in WS (Hodapp and Fisher 2017), it may in reality not be possible for teachers and practitioners to put into place WS-specific educational interventions due to the rarity of the disorder. However, seeing the overlap between WS and other developmental disorders, such as Down syndrome (DS) and Autism Spectrum Disorders (ASD) (Brown et al. 2003; Klein-Tasman et al. 2009), further research is needed whether some of the interventions and educational programmes that have shown to be successful for these disorders would also benefit children with WS. For example, although children with WS and DS show different reading difficulties, with children with WS having visual-spatial processing difficulties and those with DS showing poor phonological awareness and vocabulary, vocabulary was a significant longitudinal predictor of reading growth for both groups of children (Steele et al. 2013), and thus the Reading and Language Intervention for children with DS which includes a focus on reading and language development might also benefit reading abilities for those with WS (Burgoyne et al. 2012).

In sum, a better understanding is required of how the strengths and difficulties may benefit or hinder the educational outcomes of people with WS, in order to assess which existing interventions may benefit those with WS and which syndrome specific interventions need to be developed and evaluated through evidence-based studies.

\section{Call for Future Research}

Moving forward, it is essential that future research in WS starts building the evidence-base in relation to the educational outcomes of these children and young people and the interventions that benefit those with WS. Cross-sectional and longitudinal studies identifying the factors that predict the educational outcomes of these children and highlight potential facilitators and barriers, especially during educational transition times would be of particular importance in shaping relevant policy and practice in better addressing the needs of children with rare developmental disorders in school settings.

Another area that where there is a paucity of research concerns the views of the stakeholders in relation to the educational needs children and young people with WS. Their knowledge and awareness of the strengths and difficulties in WS is essential in addressing the complex needs of these children in educational settings. Additionally, research on the voices of children and young people with WS would also be elemental as involving them meaningfully in decision making would empower them to live as independently as possible.

To sum up, WS is a complex and rare developmental disorder which is characterised by a number of physical health problems, cognitive impairments, and mental health issues. Meeting the needs of these children in educational settings requires developing and strengthening the evidence base in relation to the educational experiences and outcomes of children and young people with WS, so as to establish the best educational provisions and intervention programmes that can support and maximise their learning and educational achievements.

Funding This study was funded by Williams Syndrome Foundation.

\section{References}

Brown, J. H., Johnson, M. H., Paterson, S. J., Gilmore, R., Longhi, E., \& Karmiloff-Smith, A. (2003). Spatial representation and attention in toddlers with Williams syndrome and down syndrome. Neuropsychologia, 41(8), 1037-1046.

Burgoyne, K., Duff, F. J., Clarke, P. J., Buckley, S., Snowling, M. J., \& Hulme, C. (2012). Efficacy of a reading and language intervention for children with down syndrome: A randomised controlled trial. Journal of Child Psychology and Psychiatry, 53, 1044-1053. https ://doi.org/10.1111/j.1469-7610.2012.02557.x.

Department for Education. (2015). Special educational needs and disability code of practice: 0 to 25 years. London: HMSO.

Department for Education (2017). Special educational needs and disability (SEND) (Available at: https://www.gov.uk/government/ policies/special-educational-needs-and-disability-send) (Accessed 16 Nov 2017).

Dunning, B. A., Martens, M. A., \& Jungers, M. K. (2015). Music lessons are associated with increased verbal memory in individuals with Williams syndrome. Research in Developmental Disabilities, 36, 565-578.

Dykens, E. M., Hodapp, R. M., \& Finucane, B. M. (2000). Genetics and mental retardation syndromes: A new look at behavior and interventions. Baltimore: Paul H Brookes Publishing.

Fidler, D. J., Lawson, J. E., \& Hodapp, R. M. (2003). What do parents want?: An analysis of education-related comments made by parents of children with different genetic syndromes. Journal of Intellectual \& Developmental Disability, 28(2), 196-204.

Fisher, M. H., \& Morin, L. (2017). Addressing social skills deficits in adults with Williams syndrome. Research in Developmental Disabilities, 71, 77-87.

Hodapp, R. M., \& Fisher, M. H. (2017). Using genetic etiology to intervene with students with intellectual disabilities. In S. Bouregy, E. 
L. Grigorenko, S. R. Latham \& M. Tan (Eds.), Genetics, ethics, and education. Cambridge University Press: Cambridge.

Howlin, P., Davies, M., \& Udwin, O. (1998). Cognitive functioning in adults with Williams syndrome. The Journal of Child Psychology and Psychiatry and Allied Disciplines, 39(2), 183-189.

Howlin, P., Elison, S., \& Stinton, C. (2009). Trajectories of cognitive, linguistic and adaptive functioning in Williams syndrome. Journal of Intellectual Disability Research, 53(10), 836-836.

Humphrey, N., \& Lewis, S. (2008). 'Make me normal': The views and experiences of pupils on the autistic spectrum in mainstream secondary schools. Autism, 12, 23-46.

Individuals with Disabilities Education Act (IDEA). (2004). USA

Järvinen, A., Korenberg, J. R., \& Bellugi, U. (2013). The social phenotype of Williams syndrome. Current Opinion in Neurobiology, 23(3), 414-422.

Klein-Tasman, B. P., Phillips, K. D., Lord, C. E., Mervis, C. B., \& Gallo, F. (2009). Overlap with the autism spectrum in young children with Williams syndrome. Journal of Developmental and Behavioral Pediatrics: JDBP, 30(4), 289.

Koehler, U., Pabst, B., Pober, B., \& Kozel, B. (2014). Clinical utility gene card for: Williams-Beuren syndrome [7q11. 23]. European Journal of Human Genetics. https://doi.org/10.1038/ejhg.2014.28.

Lindsay, G. (2007). Educational psychology and the effectiveness of inclusive education/mainstreaming. British Journal of Educational Psychology, 77, 1-24.

Lindsay, S., Proulx, M., Thomson, N., \& Scott, H. (2013). Educators' challenges of including children with autism spectrum disorder in mainstream classrooms. International Journal of Disability, Development and Education, 60, 347-362.

Martens, M. A., Wilson, S. J., \& Reutens, D. C. (2008). Research review: Williams syndrome: A critical review of the cognitive, behavioral, and neuroanatomical phenotype. Journal of Child Psychology and Psychiatry, 49(6), 576-608.

Mervis, C. B., \& Klein-Tasman, B. P. (2000). Williams syndrome: cognition, personality, and adaptive behavior. Developmental Disabilities Research Reviews, 6(2), 148-158.
Mervis, C. B., Robinson, B. F., Bertrand, J., Morris, C. A., Klein-Tasman, B. P., \& Armstrong, S. C. (2000). The Williams syndrome cognitive profile. Brain and Cognition, 44(3), 604-628.

Morris, C. A., \& Mervis, C. B. (1999). Williams syndrome. In S. Goldstein \& C. R. Reynolds (Eds.), Handbook of neurodevelopmental and genetic disorders in children (pp. 555-590). New York: The Guilford Press.

Reilly, C., Murtagh, L., \& Senior, J. (2015a). The impact on the family of four neurogenetic syndromes: A comparative study of parental views. Journal of Genetic Counseling, 24(5), 851-861.

Reilly, C., Senior, J., \& Murtagh, L. (2015b). A comparative study of educational provision for children with neurogenetic syndromes: Parent and teacher survey. Journal of Intellectual Disability Research, 59(12), 1094-1107.

Reis, S. M., Schader, R., Milne, H., \& Stephens, R. (2003). Music \& minds: Using a talent development approach for young adults with Williams syndrome. Exceptional Children, 69(3), 293-313.

Riby, D. M., Hanley, M., Kirk, H., Clark, F., Little, K., Fleck, R., ... Rodgers, J. (2014). The interplay between anxiety and social functioning in Williams syndrome. Journal of Autism and Developmental Disorders, 44(5), 1220-1229.

Riglin, L., Frederickson, N., Shelton, K. H., \& Rice, F. (2013). A longitudinal study of psychological functioning and academic attainment at the transition to secondary school. Journal of Adolescence, 36(3), 507-517.

Steele, A., Scerif, G., Cornish, K., \& Karmiloff-Smith, A. (2013). Learning to read in Williams syndrome and down syndrome: Syndrome-specific precursors and developmental trajectories. Journal of Child Psychology and Psychiatry, 54(7), 754-762.

Van Herwegen, J. (2015). Williams syndrome and its cognitive profile: The importance of eye movements. Psychology Research and Behavior Management, 8, 143. 